\title{
Anatomical factors in otoneurological dysfunction and compensation
}

\author{
Mario Milkov, Georgi Marinov \\ Prof. Paraskev Stoyanov Medical University of Varna
}

\begin{abstract}
Sharing the standpoint that physician otoneurologist should combine detailed knowledge about the anatomy, physiology and pathological physiology of central vestibular and oculomotor systems as well as about the peripheral part of vestibular and acoustic systems, the authors emphasize the necessity of knowledge about the complex anatomical links and functional relationships of these systems with the somatosensory and somatomotor systems of human organism. Otoneurologists' attention is focused on the 'trigemino-vascular system' as an anatomical and physiological substrate of migraine and accompanying headache, on comorbidity between balance disor-
\end{abstract}

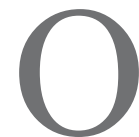

toneurology is one of young clinical interdisciplinary specialties emerged as a result from the recent fundamental discoveries in the fields of anatomy and physiology and from their transfer into ontological and neurological practice. Numerous contemporary advancements in studying the vestibular system that is considered one of the first sensory systems originating during the process of evolution but that is discovered last have contributed to the development of otoneurology (Wiest, 2015, Marinov, 2015). The causal relations between ear diseases and vertigo symptoms remained unknown until the middle of the $19^{\text {th }}$ century as the basic principles of semicircular canal function were discovered hardly several years later on. Breen \& Vrabec (2015) indicate that neurootology as an independent medical surgical specialty is even younger. The fundamentals of modern treatment of the temporal bone and of the tumours of the 'cerebello-pontine' angle are the result of pioneering works in this field since the middle of $20^{\text {th }}$ century onwards (Breen \& Vrabec, 2015). ders, anxiety disorders and migraine and on the 'trigemino-cervical system' as an anatomical and physiological substrate not only of the patients in whom the pathological alterations of upper cervical vertebrae and their connections cause painful sensations in completely intact areas such as paranasal sinuses and teeth provided with sensory innervation by the trigeminal nerve but also on the so-called 'startle reflex' as a component of reflex defense of man and animal against sudden stroke on head or sudden fall.

Key words: otoneurology, trigemino-vascular system, trigemino-cervical complex, 'startle reflex'

According to Baloh (1997), neurological symptoms are typical of migraine; however, little is known about the pathological physiology of single symptoms yet. The fact was emphasized that most symptoms occur in some patients only and the extent of manifestation of a given symptom can differ among single patients. In certain cases, only one symptom can be evident. Baloh (1997) illustrates this statement that vertigo occurs in approximately one fourth of the patients remaining even the only one sign in some cases (the so-called 'migraine equivalent') while phonophobia being the most common hearing-related symptom fluctuates, and an acute permanent hearing loss occurs in a small percentage of the patients.

Balaban et al. (2011) pay a special attention to the comorbidity between balance disorders, anxiety disorders and migraine. According to these authors, it seems that balance-anxiety relation causes the integrated activity of at least six morphological components: 
1. Processing of the interoreceptive afferent information.

2. Network of vestibular-parabrachial nuclei.

3. Processing of the vestibular and interoreceptive information from the cerebral cortex.

4. Nuclei raphe-vestibular network.

5. Nucleus coeruleus-vestibular network.

6. Raphe-locus coeruleus loop.

The aforementioned statement confirms Strupp's concept (2010) that specialists in otoneurology should combine detailed knowledge of physicians neurologists about the anatomy, physiology and pathological physiology of the central nervous system - central vestibular and oculomotor systems with that of specialists in otorhinolaryngology about the anatomy, physiology and pathological physiology of the peripheral part of vestibular and acoustic systems. In order to implement this objective, it is necessary to periodically update the existing curricula dealing with:

1. Otoneurology curriculum for students of medicine and dental medicine (Scherokman et al. 1994).

2. Postgraduate otoneurology curriculum for physicians:
a) neurologists and neurosurgeons
b) otorhinolaryngologists
c) general practitioners

3. Research and projects in the field of otoneurology.

Both contents and volume of knowledge in anatomy, physiology and pathological physiology of vestibular and acoustic systems in these curricula should timely be updated in agreement with rapidly growing new knowledge in these areas (Marinov, 2015). In our opinion, a special attention in these curricula should be paid to the 'trigemino-vascular system' and the 'trigemino-cervical system', the anatomical and physiological substrate of comorbidity between balance disorders, anxiety disorders and migraine as well as to the so-called 'startle reflex'.

\section{Trigemino-vascular system}

Recent research demonstrates that the activation of the so-called 'trigemino-vascular system' represents the anatomic substrate of migraine and accompanying headache (Goadsby et al., 2009; Espinosa-Sanchez \& Lopez-Escamez, 2015). This system incorporates nociceptive (pain-related) neurons located in the ganglion trigeminale of nervus trigeminus. Peripheral processes of these neurons are incorporated in two sensory branches of nervus trigeminus such as nervus ophthalmicus and nervus maxillaris as well as in the sensory component of the mixed nervus mandibularis. Through the branches of these neurons, sensory fibers realize the sensory innervations of the skin on anterior head half, of the mucosa of the nasal and oral cavities and of the four paranasal sinuses. The circumstance that each of these three branches of nervus trigeminus immediately prior to leaving the cranial cavity liberates a small sensory branch that innervates the adjacent parts of dura mater and pia mater and reaches the blood vessels (r. tentorii of $n$. ophthalmicus, r. meningeus of $n$. maxillaris and $r$. meningeus of $n$. mandibularis) (Fig. 1). That

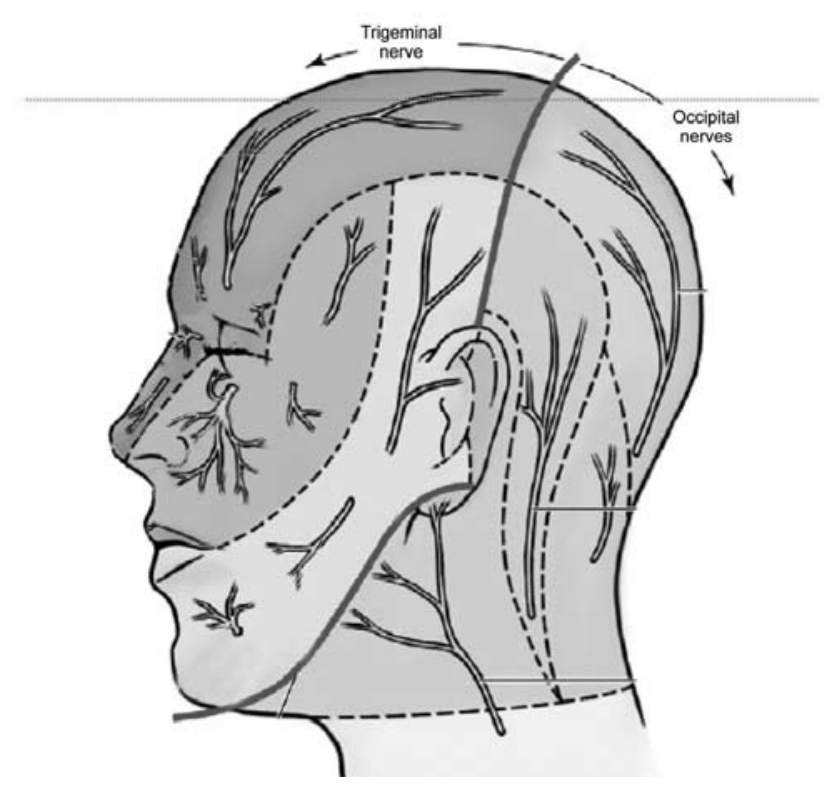

Fig. 1

is why the cerebral membranes are pain-sensitive (Ванков \& Овчаров, 2002).; Goadsby et al., 2009; Topalov et al., 2013; Espinosa-Sanchez \& LopezEscamez, 2015). These primary neurons conduct sensitivity for pain and temperature from the skin covering the anterior half of the calvaria (scalp), from the facial skin, from the mucosa of the nasal and oral cavities and of the four paranasal sinuses as well as from the cerebral membranes up to nucleus spinalis (inferior) nervi trigemini located in the pons and medulla oblongata and reaching down to the second, according some authors to the second/third cervical segment of the spinal cord. There is evidence that fibers of the upper cervical spinal neurons as well as of the nervus facialis and nervus glossopharhyngeus are also involved in the 
innervations of the cerebral membranes (Ванков \& Овчаров, 2002).

\section{Trigemino-cervical system}

Exteroceptive sensitivity for pain from the posterior occipital and anterior occipital parts of the scalp is conducted mainly through the branches of nervus occipitalis major (ramus dorsalis nervus spinalis cervicalis II) to the sensory neurons in laminae I, II and V and in laminae I and V of the gray matter of the second cervical segment of the spinal cord, respectively (Topalov et al., 2013). Experimental and clinical data indicate that there exists a 'functional continuum' between nucleus spinalis (inferior) nervi trigemini and the gray matter of the posterior horns of the initial two cervical segments of the spinal cord. These nuclei and their 'functional continuum' perceive the sensitivity for pain from the skull as well as from scalp soft tissues. Nowadays they are termed a 'trigemino-cervical complex' or 'trigemino-cervical system' (Piovesan et al., 2001; Piovesan et al., 2003) (Fig. 2).

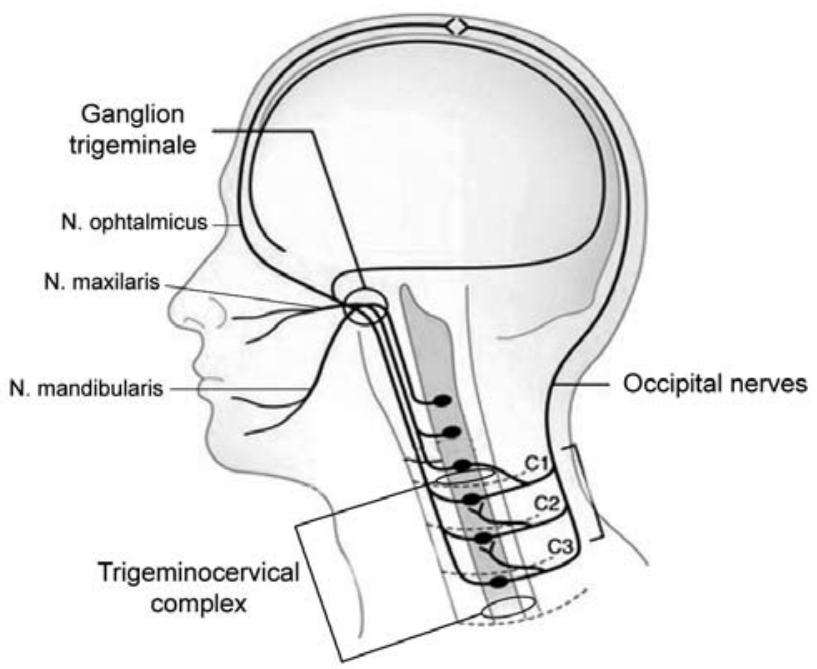

Fig. 2

Clinically, trigeminal activation causes pain sensation in the territories innervated not only by nervus trigeminus but also by nervus occipitalis major while occipital activation develops pain sensation in the cervical and trigeminal territories as well (Topalov et al., 2013; Marinov, 2015). This mutual relationship of these two neurons is known as a convergence mechanism. In recent years, a lot of data accumulates that based on this physiological phenomenon, in some patients presenting with painful symptoms typical of the diseases of the paranasal sinuses, of dental diseases, and probably, in some patients with 'migraine' pains, it deals, in fact, with pathological alterations of the upper cervical vertebrae and their connections, the painful irritations from which cause painful sensations in completely intact head areas innervated sensory by trigeminal nerve through the so-called convergence mechanism.

Cuadrado et al. (2016) show that blockades of nervus occipitalis major by using of venous anaesthesia reduces the number of the days with moderate to severe headache or with headache during the whole week, followed by elevation of the threshold for pressure-pain in the area innervated by nervus trigeminus which presupposes a central effect on the sensitivity of the inferior nucleus of this neuron.

The fibers of the second neurons located in the "trigemino-cervical system' are in ascending direction within the tractus trigeminothalamicus (quintothalamic tract) and relate with the opposite nucleus ventralis posterolateralis and nuclei posteriores (occipitales) thalami which, on their part, are projected to the primary and secondary somatosensory cortex, cortex insulae and the cortex of anterior cingulum. Besides the 'trigemino-cervical system'possesses reciprocal links with the brainstem centers involved in the processing of the nociceptive information. These centres include rostral ventromedial medulla, a group of neurons localized closely to the median line of the floor of medulla oblongata, especially of nucleus raphe magnus and ventrolateral periaqueductal gray matter and hypothalamic areas. It is accepted that these centres are incorporated in the so-called 'endogenous analgesia system'. In fact, the modulation of the 'trigemino-cervical system' depends on the descendant pathways from cerebral cortex, posterior hypothalamus and these brainstem nuclei (Akerman et al., 2011; Espinosa-Sanchez \& LopezEscamez, 2015; Marinov, 2015).

The experimental studies carried out by Bartsch \& Goadsby (2003) demonstrate that stimulation of afferent $\mathrm{C}$-fibres of dura mater results in sensibilization of second-order neurons obtaining information from cervical spinal neurons. This mechanism can participate in a procedure by which nervus trigeminus structures 'approach' cervical neuronal ones and could contribute to the clinical manifestations of cervical area hypersensitivity in migraine and cluster headache (Ruch, 1965; Arendt Nielsen et al., 2000; Bartsch \& Goadsby, 2003). 


\section{Startle Reflex}

According to experimental investigations performed by Yeomans \& Frankland (1995), the 'startle reflex' protects animals from strokes or attacks by predatory animals through a rapid contraction of the muscles of the extremities, body and dorsal neck part during the short period of time before the animal which is the object of this attack initiates defense actions or retreats. In a more recent publication, Yeomans et al. (2002) report that mechanical stimuli influencing upon the mechanoreceptors that catch the mechanical irritations to the body can simultaneously activate the trigeminal, acoustic and vestibular systems (Landis et al., 1939). These stimuli act on mechanoreceptors of different kind and localization through various mechanisms (Yeomans et al., 2002). The somatosensory system perceives the stimuli acting on the receptors in the skin or muscles. Head movements result in endolymph movement in the membranaceous vestibular labyrinth of the inner ear as well as in movement of gelatine-like cupula and membrana statoconiorum where microvilli in the shape of stereocilia and cinecilia of the sensory hair vestibular cells penetrate in. The movements of the latter induce cell irritation. The acoustic stimuli activate in an air and bone way the sensory hair cells in the cochlear membranaceous labyrinth of the inner ear. Topalov et al. (2013) argue that a strong stroke on the head or upper part of the body in man activates the acoustic, tactile and vestibular systems almost simultaneously thus inducing a reflectory change of body position, a 'cephalic apical reflex'. The reticular formation of pons plays an important role in these processes (Scott et al., 1999). The experimental studies of 'startle reflex' in rats induced by strong and sudden acoustic, vestibular or trigeminal stimuli assume that the proximity of tractus vestibulospinalis to reticulospinal pathways in the spinal cord is, probably, the neuronal basis of the modal summation of startle stimuli (Li et al., 2001).

In conclusion, we would like to emphasize that this brief analysis of the complex mutual relations between the central vestibular and oculomotor systems and the peripheral part of the vestibular and acoustic systems allow us not only to confirm Strupp's concept (2010) about their significance for the practice of the physician otoneurologist but also to supplement to them the knowledge about the complex anatomical links and functional interactions of these systems with the somatosensory and somatomotor systems of human organism. We could add the comorbidity between balance disorders, anxiety disorders and migraine for which the balance-anxiety relation plays an important role. According to Balaban et al. (2011), this requires the integrated activity of at least six morphological components.

That is why they should be the object of further research and be included into the curricula of otoneurology not only for the students of medicine and dental medicine but also for the neurologists, neurosurgeons, otorhinolaryngologists and general practitioners.

\section{Книгопис}

1. Akerman, S., P.R. Holland, P.J. Goadsby. Diencephalic and brainstem mechanisms in migraine. Nat. Rev. Neurosci. $2011 ; 12: 570-584$.

2. Arendt Nielsen, L., Laursen RJ, Drewes AM. Referred pain as an indicator for neural plasticity. Prog Brain Res 2000;129:343-356.

3. Balaban, C. D., R. G. Jacob, J. M. Furman. Neurologic bases for comorbidity of balance disorders, anxiety disorders and migraine: neurotherapeutic implications. Expert review of neurotherapeutics, 2011;11(3):379-394.

4. Baloh, R.W. Neurotology of migraine. Headache: The Journal of Head and Face Pain, 1997;37(10):615-621.

5. Bartsch, T., P.J. Goadsby. Increased responses in trigeminocervical nociceptive neurons to cervical input after stimulation of the dura mater. Brain, 2003;126(8):1801-1813.

6. Breen, J.T., J.T. Vrabec. Early Practice: Neurotology. Otolaryngologic Clinics of North America. 2015;48(2):257-262.

7. Cuadrado, M. L., Б. Aledo-Serrano, P. Navarro, P. Lypez-Ruiz, C. Fernбndez-de-las-Pecas, I. Gonzбlez-Suбrez,... C. Fernбndez-Pйrez. Shortterm effects of greater occipital nerve blocks in chronic migraine: A double-blind, randomized, placebo-controlled clinical trial. Cephalalgia, 2016;0333102416655159.

8. Espinosa-Sanchez, J.M., J.A. Lopez-Escamez. New insights into pathophysiology of vestibular migraine. Frontiers in Neurology. Headache Medicine and Facial Pain. 2015; 6(Art. 12):1-6.

9. Goadsby, P.J., A.R. Charbit, A.P. Andreou, S. Akerman, P.R. Holland. Neurobiology of migraine. Neuroscience. $2009 ; 161(2): 327-341$.

10. Landis, C., W.A. Hunt. The startle pattern. New York: Ferrar and Rinehart, 1939. Cited by: Yeomans et al. 2002.

11. Li, L., S. Stiedl, J.S. Yeomans. Neuroscience, 2001;106(4):811-821.

12. Marinov, G. Anatomical considerations in otoneurological dysfunction and compensation. Varna Neurootological days, Varna, 2324.04.2015. 
13. Piovesan, E.J., P.A. Kowacs, C.E. Tatsui, M.C. Lange, Ribas, L.C. Werneck. Referred pain after painful stimulation of the greater occipital nerve in humans: evidence of convergence of cervical afferences on trigeminal nuclei. Cephalalgia. 2001;21(2):107-109.

14. Piovesan, E.J., P.A. Kowacs, M.L. Oshinsky. Convergence of cervical and trigeminal sensory afferents. Current pain and headache reports. 2003;7(5):377-383.

15. Ruch, T.C. Pathophysiology of pain. In: Ruch TC, Patton HD, editors. Physiology and biophysics. 19th edn. Philadelphia: Saunders; 1965. pp. 345-363.

16. Scherokman, B., K. Cannard, J.Q. Miller, AAN Undergrad education Committee - Adapted from. Otoneurology Curriculum for Medical Students What should a graduating medical student know about neurology ? Neurology 1994;44:1170-1176.

17. Scott, B.W., P.W. Frankland, L. LI, J.S. Yeomans. Neuroscience, 1999;91(4):1565-1574.

18. Strupp, M. Challenges in neuro-otology. Frontiers in neurology. 2010;1:121. Published online 2010 Oct 11. doi: 10.3389/fneur.2010.00121

19. Topalov I., V. Golemansky, G. Marinov. On the cephalic apical reflex. Evolutionary aspects. Comptes rendus de l'Academie bulgare des sciences. 2013;66(12):1751-1760.

20. Wiest, G. The origins of vestibular science. Ann New York Academy of Sciences. 2015;1343(1):1-9.

21. Yeomans, J. S., L. Li, B. W. Scott, P. W. Frankland. Tactile, acoustic and vestibular systems sum to elicit the startle reflex. Neuroscience \& Biobehavioral Reviews. 2002;31;26(1):1-1.

22. Yeomans, J. S., P.W. Frankland. The acoustic startle reflex: neurons and connections. Brain research reviews. 1995;30;21(3):301-314.

23. Ванков, В., В. Овчаров. Анатомия на човека. Медицинско издателство АРСО. 2002, 739 стр.

\section{Corresponding author:}

Assoc. Prof. Mario Miluov, MD, PhD

Medical University „Paraskev Stoyanov“, Varna 9002, BG

Tzar Osvoboditel street, 84

mario.milkov@gmail.com 